\title{
Unidades lexicais que designam enfermidades cutâneas: um estudo metalexicográfico da variação em perspectiva histórica
}

\author{
Lexical units designing cutanean nurses: a metalexicographical study of variation \\ study of variation in historic perspective
}

Carolina Domladovac SILVA* Universidade Estadual Paulista (UNESP)

\author{
Clotilde de Almeida Azevedo MURAKAWA** \\ Universidade Estadual Paulista (UNESP)
}

\begin{abstract}
RESUMO: O presente artigo tem por objetivo elaborar um estudo metalexicográfico da variação linguística em perspectiva histórica. Por meio da análise semântico-lexical de algumas unidades lexicais relativas a doenças que acometiam a população, no contexto da mineração, no Brasil Colonial, mediante a observação de uma situação da língua escrita, verificam-se os aspectos referentes à variação de diferentes denominações de unidades lexicais - gonorreia, esquentamento e purgação - relativas a uma mesma enfermidade cutânea. As abreviaturas, no âmbito megaestrutural, e as marcas de uso, no microestrutural, revelam-se como parte essencial da definição em dicionários, recebendo atenção especial pela informação extralinguística contida, levando-se em conta as diferenças que permeiam o universo das obras. Por este viés sócio-histórico, buscar-se-á verificar se ocorreu mudança linguística em alguma destas unidades.
\end{abstract}

PALAVRAS-CHAVE: Metalexicografia. Variação Linguística. Definição. Enfermidades cutâneas.

\footnotetext{
* Aluna do curso de Doutorado do Programa de Pós-graduação em Linguística e Língua Portuguesa, na Faculdade de Ciências e Letras da Universidade Estadual Paulista Júlio de Mesquita Filho (UNESP), campus de Araraquara-SP. Bolsista CAPES. E-mail: caroldomla@gmail.com

** Possui graduação em Letras pela Faculdade de Filosofia, Ciências e Letras de Jahu Fundação Educacional de Jahu (1969), mestrado em Letras, Linguística e Língua Portuguesa pela Universidade Estadual Paulista Júlio de Mesquita Filho, Araraquara (1984) e doutorado em Letras, Linguística e Língua Portuguesa pela Universidade Estadual Paulista Júlio de Mesquita Filho, Araraquara (1991). Atualmente é professor assistente doutor da Universidade Estadual Paulista Júlio de Mesquita Filho. Tem experiência na área de Letras, com ênfase em Língua Portuguesa, atuando principalmente nos seguintes temas: lexicografia, lexicologia, linguística histórica e semântica. E-mail: jtm.jau@uol.com.br
} 


\begin{abstract}
This article aims to elaborate a metalexicographic study of linguistic variation in historical perspective. Through the semantic-lexical analysis of some lexical units related to diseases that affected the population, in the context of mining, in Colonial Brazil, by observing a situation of the written language, we verified the aspects related to the variation of different denominations of lexical units - gonorrhea, warming and purging - related to the same skin disease. Abbreviations in the mega-structural scope and use marks in the microstructural are revealed as an essential part of the dictionary definition, receiving special attention for the extralinguistic information contained, taking into account the differences that permeate the universe of works. Through this socio-historical bias, it will be sought to verify if linguistic change occurred in any of these units.
\end{abstract}

KEYWORDS: Metalexicography. Linguistic Variation. Definition. Skin diseases.

\title{
Introdução
}

No contexto histórico de setecentos no Brasil, o grande número de habitantes que se concentrou nas Minas Gerais, devido à descoberta do ouro, serviu de laboratório para a observação médica, ao longo do século. Entre os imigrantes motivados pela ideia de "fazer fortuna", chegavam também de Portugal cirurgiões e cirurgiões-barbeiros, os quais se tornaram essenciais, tendo em vista as precárias condições de vida na época.

Seguindo os pressupostos da Linguística de Corpus e buscando representar uma parte da realidade linguística dos séculos XVI, XVII e XVIII, no Brasil, foi a partir da coleta e da seleção de diversos tipos de textos impressos sobre o Brasil Colonial, produzidos por portugueses aqui radicados ou que aqui estiveram, que se iniciou a construção do Banco de Dados do Dicionário Histórico do Português do Brasil séculos XVI, XVII e XVIII - doravante Banco de Dados do DHPB - mediante modelo informatizado.

Este banco é constituído de 7.492 .472 ocorrências de palavras, cujo volume de textos somou 23.858 páginas digitalizadas. Atualmente, um segundo banco de dados complementa o primeiro, reunindo mais 2.049.249 ocorrências e somando mais 8.009 páginas digitalizadas (BIDERMAN; MURAKAWA, não publicado, Apresentação), o 
que comprova a possibilidade de atualização constante de um corpus, prevista por Biderman (2001, p. 80).

Dentre o copioso volume de textos que compõem o Banco de Dados do DHPB, selecionamos como objeto para este estudo as obras intituladas Erário Mineral (FERREIRA, 1735); Prodigiosa Lagoa descuberta nas Congonhas das Minas do Sabará, que tem curado a varias pessoas dos achaques, que nesta Relação se expõem (MIRANDA, 1749) e Governo de mineiros, mui necessário para os que vivem distantes de professores seis, oito, dez e mais léguas, padecendo por essa cauza is seus domésticos e escravos queixas, que pela dilaçam dos remédios se fazem incuráveis, no mais das vezes mortais (MENDES, 1770), elaboradas por cirurgiões-barbeiros portugueses, referentes ao período da mineração em Minas Gerais, no Brasil Colonial, editadas e publicadas pela primeira vez em Lisboa. A partir da leitura sobre a medicina praticada na Europa, da arguta observação dos costumes locais e dos recursos utilizados por índios e negros, tais cirurgiões-barbeiros não só descreviam minuciosamente os principais males frequentes em Minas, como também experimentavam e propunham meios eficazes de cura. Traziam, portanto, algum alívio e conhecimento à população das minas carente de qualquer assistência à saúde. Suas obras foram, assim, elaboradas com o intuito de associar o tratamento de várias enfermidades - causadas pela insalubridade do trabalho nas minas, pela falta de higiene, pelo ambiente tropical etc. - às plantas, aos animais e aos produtos da terra.

Nosso objetivo é, assim, elaborar um estudo metalexicográfico da variação em perspectiva histórica, por meio da análise semântico-lexical de algumas unidades lexicais relativas a uma das enfermidades cutâneas que acometiam a população, no contexto da mineração, no Brasil Colonial.

\section{Pressupostos teóricos}

A Lexicografia caracteriza-se como um campo multidisciplinar, uma vez que mantém estreita relação com outras disciplinas linguísticas, como a Semântica (no que se refere aos estudos do significado) e a Sociolinguística (no que tange à variação lexical, por exemplo). 
A Metalexicografia, em termos gerais, é o conjunto de reflexões teóricas e procedimentos metodológicos para a compilação de obras lexicográficas.

A Sociolinguística compreende um ramo da Linguística que estuda todos os aspectos da relação entre língua e sociedade e, assim como a Dialetologia, que analisa, prioritariamente, a relação existente entre a língua e o espaço geográfico, reconhece a existência da heterogeneidade linguística, isto é, as diferenças da língua falada em determinados grupos sociais que, de maneira geral, ocorrem devido a três fatores: o social, o geográfico e o situacional.

De acordo com Matoré (1953), o objetivo da Lexicologia é particular, parte do estudo do vocabulário para tentar explicar uma sociedade. $O$ autor afirma que a Lexicologia pode ser definida como uma disciplina sociológica que utiliza as palavras enquanto material linguístico. Desta forma, as palavras são consideradas por ele como o reflexo de um estado da sociedade.

Cambraia (2013, p. 183) afirma que, apesar das lacunas encontradas na teoria de Matoré, "é possível, sim, articular critérios internos (semânticos) e externos (sociais) para representar a estrutura do léxico de uma época [...]”.

Por este viés sócio-histórico, buscou-se compreender se houve mudança linguística em alguma das unidades lexicais selecionadas.

\section{Metodologia}

Esta pesquisa verificou, por meio da observação de uma situação da língua escrita, os aspectos referentes à variação semântico-lexical, de diferentes denominações de lexemas relativos ao sistema tegumentar do corpo humano, para se referir a uma enfermidade cutânea.

O trabalho foi realizado com base no "Vocabulário das enfermidades no Erário Mineral (1735), de Luís Gomes Ferreira” (DOMLADOVAC-SILVA, 2017, p. 65-171), em cuja nomenclatura encontram-se as denominações para as doenças que acometiam a população de Minas Gerais, no período do Brasil Colonial. Tal vocabulário contempla tanto as unidades lexicais da época e suas possíveis variantes como as unidades lexicais equivalentes pertencentes ao discurso médico contemporâneo, relativas às enfermidades 
que ocorrem na obra, classificadas segundo o sistema do corpo humano em que se manifestam.

Fizemos para o presente trabalho não somente um recorte do sistema tegumentar que compõe o referido vocabulário como também escolhemos algumas variadas formas representativas da mesma doença, visando, assim, ao exercício prático de metodologias adotadas tanto pela Semântica como pela Socioterminologia, refletidas em algumas análises dos dados coletados. As unidades lexicais selecionadas para este trabalho foram: gonorreia, esquentamento, e purgação.

Em contrapartida, ampliamos o corpus de estudo e verificamos a ocorrência e o significado de tais unidades nas três obras supracitadas, escritas por cirurgiões-barbeiros em atividade na região de extração do ouro, no século XVIII.

Os trechos retirados das obras são de suma importância, pois conservam características específicas de um vocabulário local, em que se buscou a diferença de denominações para os referidos lexemas, uma vez que cada indivíduo nomeia algo de acordo com sua vivência e conhecimento de mundo.

Fez-se útil ainda a consulta a dicionários da língua portuguesa para a análise das definições das unidades lexicais, com o intuito de verificar se, porventura, houve ampliação ou redução semântica, mais especificamente:

- Dicionário eletrônico Houaiss da língua portuguesa 2009.3 - doravante Houaiss -, de Antonio Houaiss e Mauro de Salles Villar (2009);

- Dicionário Histórico do Português do Brasil - séculos XVI, XVII e XVIII $(C N P q)$ - doravante DHPB -, de Maria Tereza Camargo Biderman e Clotilde de Almeida Azevedo Murakawa (não publicado).

A microestrutura dos dicionários selecionados registra algumas informações sobre a expressão do signo, bem como algumas informações de ordem pragmática, a saber:

- O Houaiss destaca informações etimológicas, a categoria gramatical, o gênero, as marcas linguísticas (diatécnicas, diatópicas, diafásicas), além de ordenar numericamente suas acepções; o dicionário é abundante na sinonímia e, por ser eletrônico, oferece ainda a opção de utilização de cores para distinção de cada informação da microestrutura. 
- O DHPB registra a categoria gramatical, o gênero, as variantes, as acepções ordenadas numericamente, as expressões sintagmáticas (e/ou locuções) e a primeira datação (primeira vez que a unidade ocorre no banco de dados organizado para a elaboração deste dicionário). No DHPB, tanto as variantes gráficas como as diferentes nuances de sentido aparecem abonadas e acompanhadas das respectivas informações: autor do texto, datação, obra, código e página relacionados à organização do banco de dados, de onde foi retirada ${ }^{\mathbf{1}}$.

O dicionário Houaiss auxilia-nos enquanto parte do discurso moderno. O DHPB, elaborado com base em textos antigos, justifica sua utilização no que se refere à definição das unidades lexicais selecionadas, fundamentada no universo discursivo do século XVIII. A obra, embora ainda inédita, portanto mais recente em relação ao dicionário Houaiss, traz definições que se assentam no valor semântico das palavras no período considerado, e serviram para documentar possíveis variações semânticas, uma vez que abarcam o léxico de um período mais antigo (séculos XVI, XVII e XVIII).

As abreviaturas, no âmbito megaestrutural, e as marcas de uso, no microestrutural, revelam-se como parte essencial da definição em dicionários, recebendo atenção especial pela informação extralinguística contida, levando-se em conta as diferenças que permeiam o universo das obras.

A variação diatécnica recebe atenção especial no dicionário Houaiss, uma vez que se buscam registrar os usos relativos a um domínio do saber ou área de conhecimento de modo mais amplo, utilizando-se, para indicação das variantes, marcas de uso, na forma de abreviaturas, que dão conta dos domínios e das principais subáreas.

\section{Resultados}

A unidade lexical gonorreia é definida nos dicionários consultados da seguinte maneira (quadro 1):

Quadro 1: Definições de gonorreia.

\footnotetext{
${ }^{1}$ Todos os exemplos retirados deste banco de dados seguem a mesma configuração. 


\begin{tabular}{|c|c|}
\hline dicionário & definição \\
\hline DHPB & $\begin{array}{l}\text { gonorreia s.f. } \\
\text { variantes: gonorréia, gonorrea, gonorreya, gonorrhea, gonorrhéa, } \\
\text { gonorrheya. } \\
\text { Corrimento mucoso pelos órgãos genitais masculinos ou femininos, } \\
\text { provocado por infecção. } \\
\text { Me disse êle, em francês, que vinha doente de um «chou de pice» ou } \\
\text { gonorréia e que pelo agasalho que eu lhe fazia me recomendava muito } \\
\text { me abstivesse das «filie de honneur» de Mato Grosso, porque não só } \\
\text { êle, senão todos os que vinham traziam o mesmo mal. ANTÔNIO } \\
\text { PIRES DA SILVA PONTES (1964) [1781], III - DOCUMENTOS - 5. } \\
\text { DIÁRIO HISTÓRICO E FÍSICO DA VIAGEM DOS OFICIAIS DA } \\
\text { DEMARCAÇÃO QUE PARTIRAM DO QUARTEL GENERAL DE } \\
\text { BARCELOS PARA A CAPITAL DE VILA BELA DA CAPITANIA } \\
\text { DE MATO GROSSO, EM 1 DE SETEMBRO DE 1781. POR } \\
\text { ANTÔNIO PIRES DA SILVA PONTES. (COLEÇÃO MARCOS DE } \\
\text { MENDONÇA, DE DOCUMENTOS) [A00_1138 p. 369]. } \\
\text { sulgam ser efficaz em todo o fluxo de sangue por qualquer cauza que } \\
\text { maior parte das enfermidades. FRANCISCO ANTÔNIO DE } \\
\text { lienteria em que faz maravilhofos effeytos: cura certiflimante as } \\
\text { purgaçoens das mulheres, ou fejaõ brancas, ou verdes, ou amarellas: } \\
\text { cura as gonorreas por mais antigas, e obftinadas que fejaõ: cura aos } \\
\text { que fe vafaõ em fangue pelas almorreymas [...]. LUIS GOMES } \\
\text { FERREIRA (1735) [1735], DA MISCELLANIA DE VARIOS } \\
\text { REMEDIOS, AIIIM EXPERIMENTADOS, E INVENTADOS PELO }\end{array}$ \\
\hline
\end{tabular}




\begin{tabular}{|c|c|}
\hline & 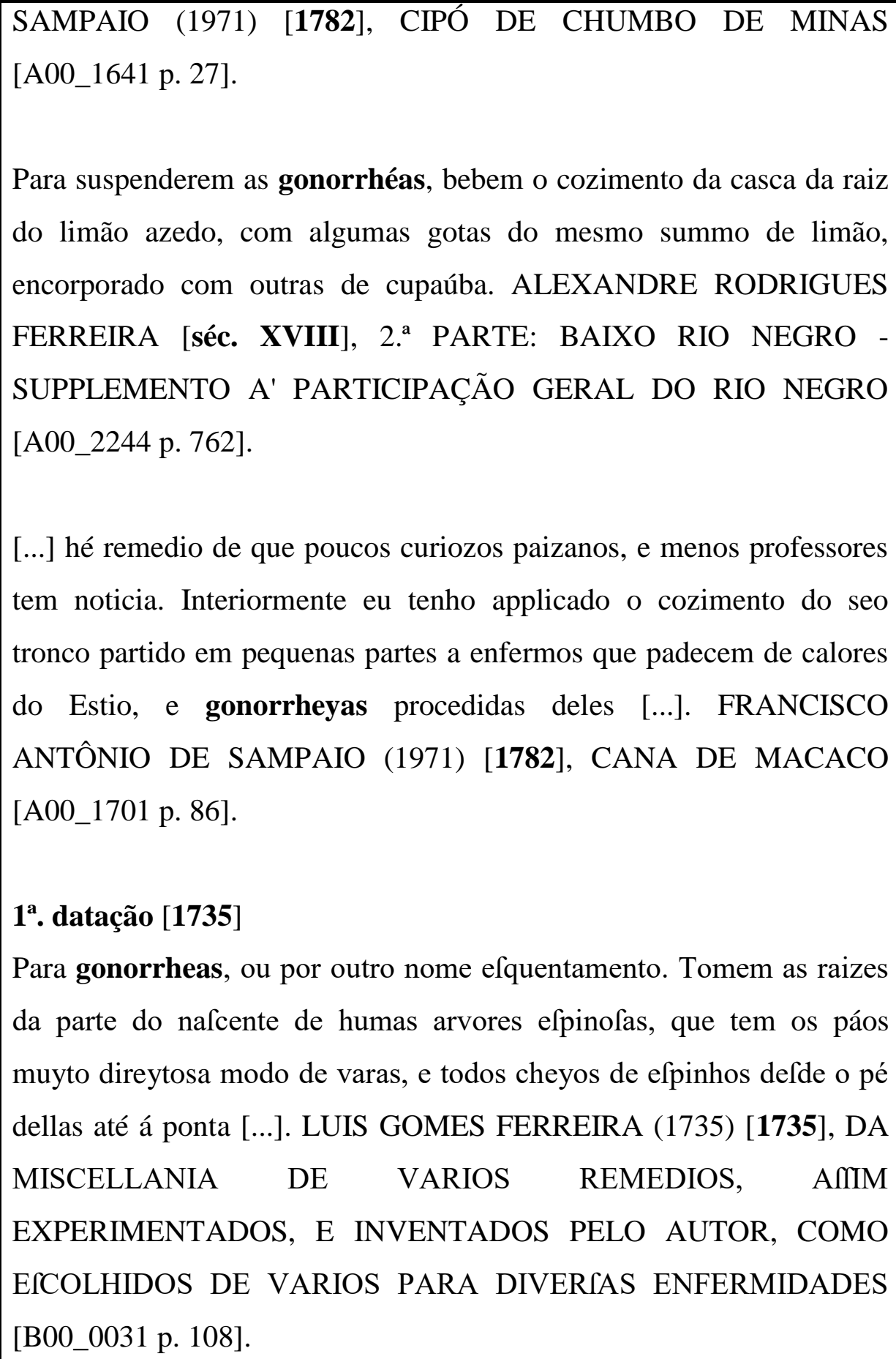 \\
\hline Houaiss & $\begin{array}{l}\text { gonorreia } \\
\text { léil s.f. (1661) DERM INFECT m.q. blenorragia } \square \text { ETIM gr. } \\
\text { gonórrhoia,as 'id.', pelo lat. gonorrhoea,ae 'id.' } \square \text { SIN/VAR } \\
\text { blenorragia, esquentamento, pingadeira, purgação }\end{array}$ \\
\hline
\end{tabular}

Fonte: elaboração própria. 
Embora os exemplos contemplados no DHPB associem a denominação gonorreia a outras, como esquentamento ou purgação, é o Houaiss que comprova a sinonímia ou variação (SIN/VAR) por meio destas unidades lexicais. Além disso, Houaiss indica que se trata de uma doença relativa à pele, através da rubrica temática "DERM", abreviatura de Dermatologia.

Se observarmos a definição de blenorragia, que por sua vez define gonorreia, em Houaiss, podemos perceber que o binômio que denomina a bactéria causadora da doença deriva desta última:

\author{
blenorragia \\ s.f. (1836) DERM INFECT doença sexualmente transmissível, provocada \\ pela bactéria Gram-negativa Neisseria gonorrhea, no homem, ger. \\ caracterizada por uretrite, na mulher, por corrimento mucoso e nos recém- \\ nascidos, por oftalmia gonocócica; gonorreia, gonococcia, gonococia \\ ETIM bleno- + -rragia $\square$ SIN/VAR ver sinonímia de gonorreia (HOUAISS, \\ 2009, grifo nosso).
}

Enquanto no século XVIII gonorreia era associada aos elementos mórficos gon $(o)$ - + -reia, que em Houaiss possuem os seguintes significados:

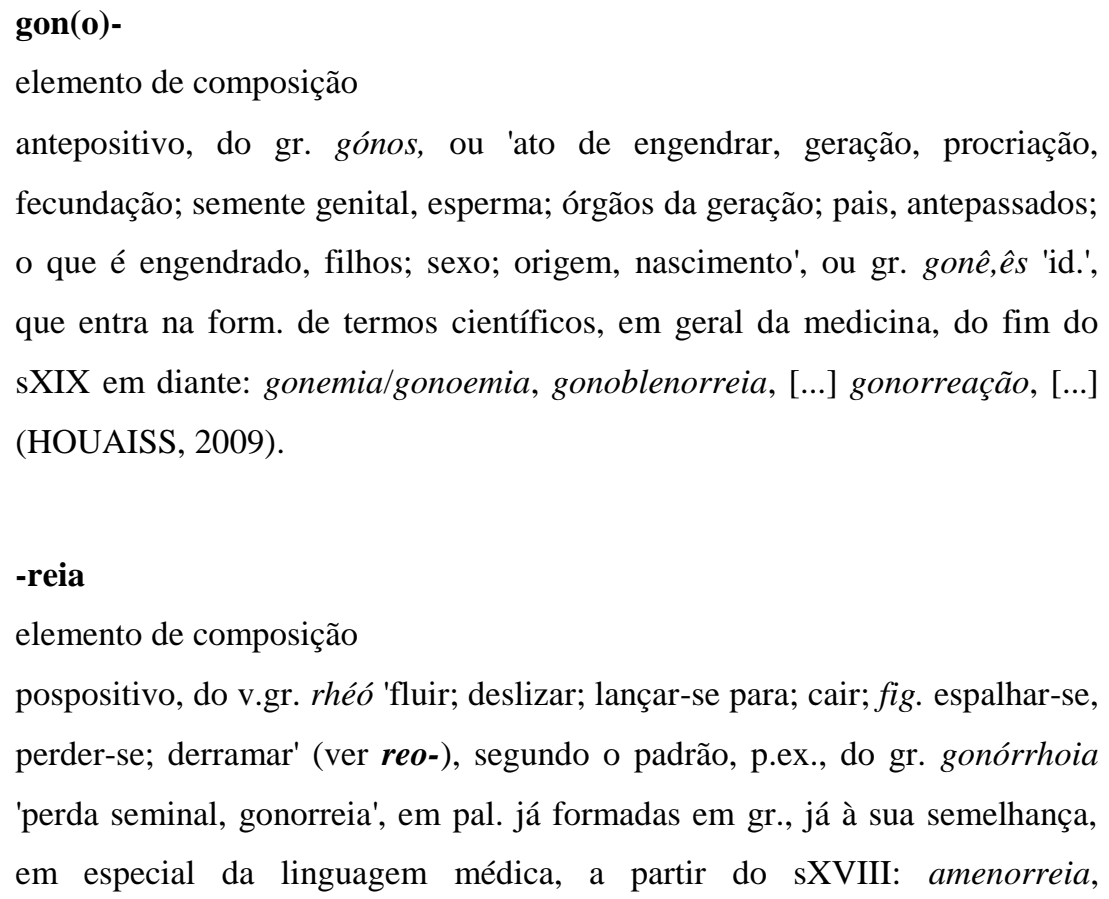
sXIX em diante: gonemia/gonoemia, gonoblenorreia, $[\ldots]$ gonorreação, $[\ldots]$ (HOUAISS, 2009).

\section{-reia}

elemento de composição

pospositivo, do v.gr. rhéó 'fluir; deslizar; lançar-se para; cair; fig. espalhar-se, perder-se; derramar' (ver reo-), segundo o padrão, p.ex., do gr. gonórrhoia 'perda seminal, gonorreia', em pal. já formadas em gr., já à sua semelhança, em especial da linguagem médica, a partir do sXVIII: amenorreia, 
balanorreia, blenorreia, diarreia, dismenorreia, espermatorreia, esteatorreia, galactorreia, gastrorreia, gonorreia, [...] (HOUAISS, 2009).

Blenorragia, termo mais atual (século XIX) é composto pelos elementos mórficos blen(i/o)- + rragia, que por sua vez representam:

\author{
blen(i/o)- \\ elemento de composição \\ antepositivo, do gr. blénnos,eos-ous 'humor viscoso, muco, corrimento \\ (purulento)' e gr. blennós,ê,ón 'que baba, que expele baba; idiota', em pal. \\ científicas, muitas da área médica, do sXIX em diante: [...] blenorragia, \\ blenorrágico, blenorreia, blenorreico, [...]; como pospositivo, há em \\ iscoblenia (HOUAISS, 2009).

\section{-rragia} \\ elemento de composição \\ pospositivo, do gr. -rrhagia, der. do v. rhêgnumi 'escoar, jorrar'; ocorre em \\ cultismos da terminologia médica, do sXIX em diante, com a acp. de \\ 'escoamento, ou corrimento súbito e abundante, ger. anormal, fluxo do \\ líquido orgânico designado pelo primeiro elemento': blenorragia, \\ hemorragia, hidrorragia, [...] (HOUAISS, 2009).
}

Dessa maneira, podemos inferir que a denominação gonorreia está ligada à ideia de onde se dá a doença, enquanto blenorragia, à maneira como ocorre.

Blenorragia ocorre uma vez (freq. 1) no Banco de dados do $\mathrm{DHPB}^{2}$, por meio de uma variante gráfica ("blenorrhagias"). O contexto em que ocorre comprova a sinonímia de gonorreia, já que também é associada a esquentamento, além de atestar que a unidade lexical entra em uso no século XIX (1801):

Omitto aqui a virtude anthelmintica, que lhe attribue Strak, e a dessecante nas Blenorrhagias ou esquentamentos, que observou Swediaur, porque estas naõ estaõ ainda taõ bem contestadas: [...]. BERNARDINO ANTONIO GOMES (1801) [1801], DAS VIRTUDES DA IPECAC [A00_1336 p. 25].

\footnotetext{
${ }^{2}$ A unidade lexical não foi contemplada na nomenclatura do DHPB por tratar-se de um hapax legomena. 
O DHPB elenca seis variantes ${ }^{3}$ para essa unidade lexical - gonorréia, gonorrea, gonorreya, gonorrhea, gonorrhéa, gonorrheya - por meio das quais já se podem perceber traços da variante etimológica da palavra, conforme informa Houaiss. A $1^{\text {a }}$ datação da palavra, no DHPB, refere-se ao Erário Mineral (FERREIRA, 1735), onde, além da lexia gonorrheas (freq. 4), ocorrem também gonorrhea (freq. 4) e gonorrea (freq. 1).

Na Prodigiosa Lagoa (MIRANDA, 1749), a unidade lexical não aparece. No Governo de Mineiros (MENDES, 1770), a unidade ocorre nas formas gonorrea (freq. 2) e gonorreas (freq. 2), também associada a esquentamento:

\begin{abstract}
Remedio para gonorreas, a que o vulgo chama efquentamentos. Aflim que apontar a gonorrea, principie o enfermo a tomar todas as manhans em jejum huma boa chicara da fua mefma ourina, e continúe fem falta dez manhans, naõ comendo, nem bebendo fem paffarem duas horas; e no fim dos ditos dez dias eftará faõ, e livre, naõ fó da queixa, mas do que della fe coftuma feguir: coma neftes dias carne frefca. JOSÉ ANTONIO MENDES (1770) [1770], CAPITULO XV - E ULTIMO DESTA OBRA, EM QUE VOS QUERO NOTICIAR MUITOS REMEDIOS PARA VARIAS QUEIXAS, E O MODO COMO OS DEVEIS UZAR, E DESCOBRIRVOS ALGUNS SEGREDOS, COM OS QUAES TENHO BOAS CURAS, E TODOS BEM EXPERIMENTADOS [A00_2405 p. 121].
\end{abstract}

Embora haja um termo mais atual para gonorreia, não se pode dizer que houve mudança, uma vez que se nota que a unidade lexical é mais usada que a variante blenorragia. Tal fato pode ser constatado nas definições de Houaiss para as unidades lexicais escolhidas, em que podemos notar a remissão à unidade gonorreia, e não à blenorragia.

Observemos as definições para esquentamento (quadro 2):

Quadro 2: Definições de esquentamento.

dicionário

\footnotetext{
${ }^{3}$ As variantes de uma palavra-entrada registradas pelo DHPB constituem todas as formas que esta pode apresentar nos diversos contextos do banco de dados e podem ser gráficas, morfológicas ou fonéticas. (BIDERMAN; MURAKAWA, não publicado, Apresentação).
}

Revista Moara, n. 55, jan-jul 2020 ISSN: 0104-0944

Recebido em19/01/2020

Avaliado em 11/07/2020 


\begin{tabular}{|c|c|}
\hline & 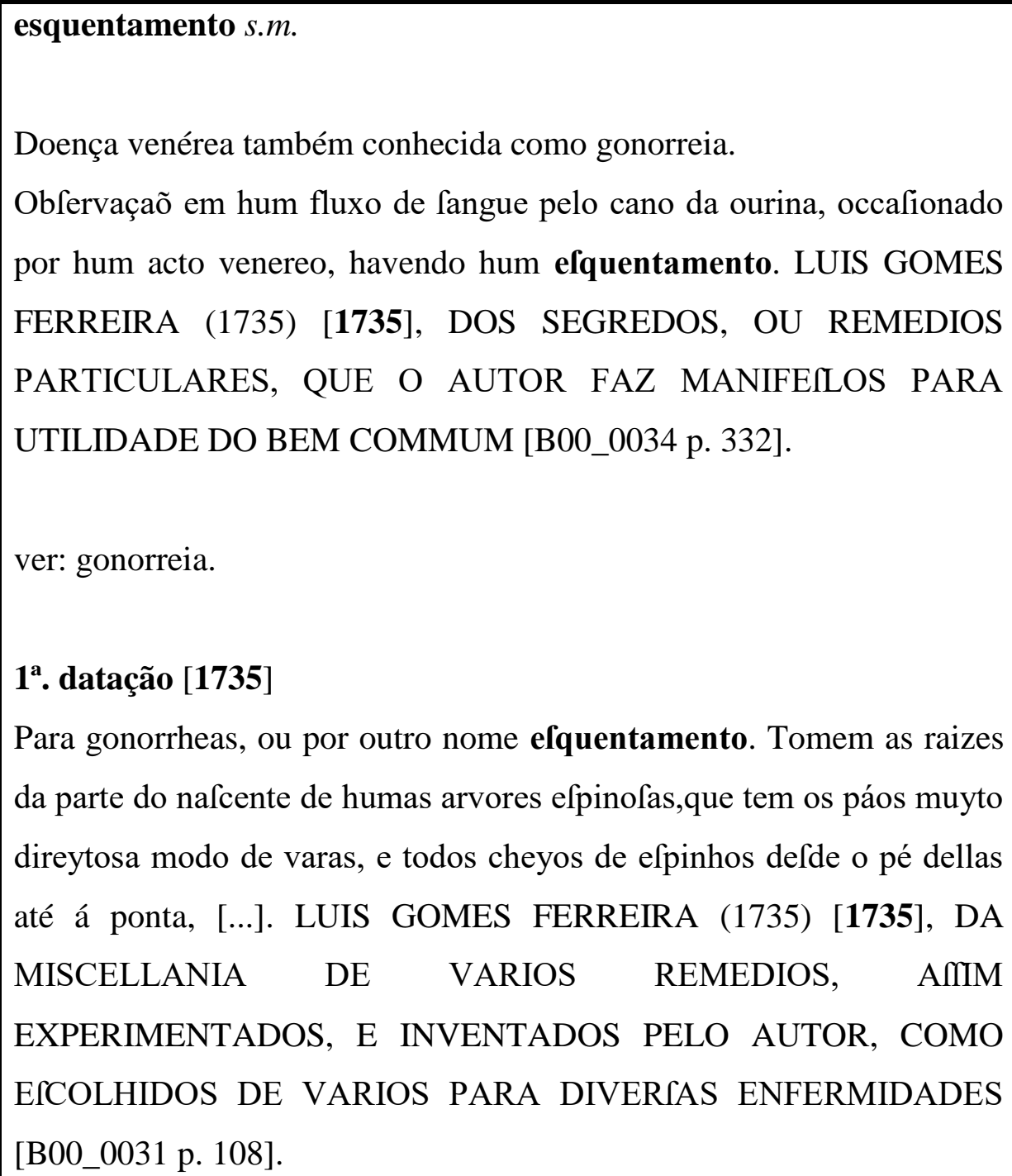 \\
\hline Houaiss & $\begin{array}{l}\text { esquentamento } \\
\text { s.m. (sXIV) } 1 \text { ato ou efeito de esquentar(-se) } 2 \text { irritação, raiva, briga } 3 \\
\text { excitação, estimulação, assanhamento } 4 \text { tab. m.q. gonorreia } 5 \text { ICT } \\
\text { m.q. boquinha (Paranthias furcifer) } \square \text { ETIM esquentar + -mento } \square \\
\text { SIN/VAR aquecimento, calorificação, esquentação, esquentada; ver tb. } \\
\text { sinonímia de gonorreia } \square \text { ANT esfriamento }\end{array}$ \\
\hline
\end{tabular}

Fonte: elaboração própria.

Nesse caso, o DHPB define a unidade lexical por meio de sua sinônima gonorreia, além de remetê-la ao verbete ("ver: gonorreia"). No corpus do DHPB, portanto, esquentamento aparece somente com essa acepção. A $1^{\mathrm{a}}$ datação da palavra refere-se também ao Erário Mineral (FERREIRA, 1735), onde a unidade é grafada com 
$\int$ ('s longo') - este, por sua vez, não considerado como traço variacional no DHPB - e ocorre seis vezes no singular e nove, no plural (freq. 15). Tal frequência de uso comprova que essa unidade lexical era mais usada no século XVIII para reportar a doença.

Tanto na Prodigiosa Lagoa (MIRANDA, 1749), quanto no Governo de Mineiros (MENDES, 1770), a unidade lexical esquentamento só ocorre uma vez, também grafada com 's longo', no singular e no plural, respectivamente:

\begin{abstract}
Hum efcravo do Padre João de Araujo, do Inficionado, com hum efquentamento, que trazia ha feis para fete annos, com trez banhos, que tomou, teve melhoras. JOÃO CARDOSO DE MIRANDA (1749) [1749], PRODIGIOSA LAGOA DESCUBERTA NAS CONGONHAS DAS MINAS DE SABARÁ, QUE TEM CURADO A VARIAS PESSOAS DOS ACHAQUES, QUE NESTA RELAÇÃO SE EXPÕEM [B00_0023 p. 19].
\end{abstract}

Remedio para gonorreas, a que o vulgo chama efquentamentos. JOSÉ ANTONIO MENDES (1770) [1770], CAPITULO XV - E ULTIMO DESTA OBRA, EM QUE VOS QUERO NOTICIAR MUITOS REMEDIOS PARA VARIAS QUEIXAS, E O MODO COMO OS DEVEIS UZAR, E DESCOBRIRVOS ALGUNS SEGREDOS, COM OS QUAES TENHO BOAS CURAS, E TODOS BEM EXPERIMENTADOS [A00_2405 p. 121].

No último exemplo, o sentido de esquentamento é claramente associado a gonorreia, indicando também o registro de uso do vulgo.

Em Houaiss, no entanto, somente a quarta acepção do verbete refere-se à doença e é marcado, no campo da definição, como tabuísmo (“tab.”), que para Houaiss e Villar (2009, Detalhamento dos verbetes e outras informações, p. 4) indica a faixa linguística de expressão em que a palavra ou a acepção é empregada, no caso, "palavras que por convenção têm uso considerado pesadamente grosseiro ou ofensivo - os palavrões". Não somente a definição ("m.q. gonorreia”), como também a sinonímia da palavra remetem-na a gonorreia ("ver tb. sinonímia de gonorreia"), em que, por sua vez, não há menção a tabu.

Outro sinônimo referido por Houaiss à gonorreia é purgação. Vejamos como é definida a unidade pelos dicionários em estudo (quadro 3): 
Quadro 3: Definições de purgação.

\begin{tabular}{|c|c|}
\hline dicionário & definição \\
\hline DHPB & 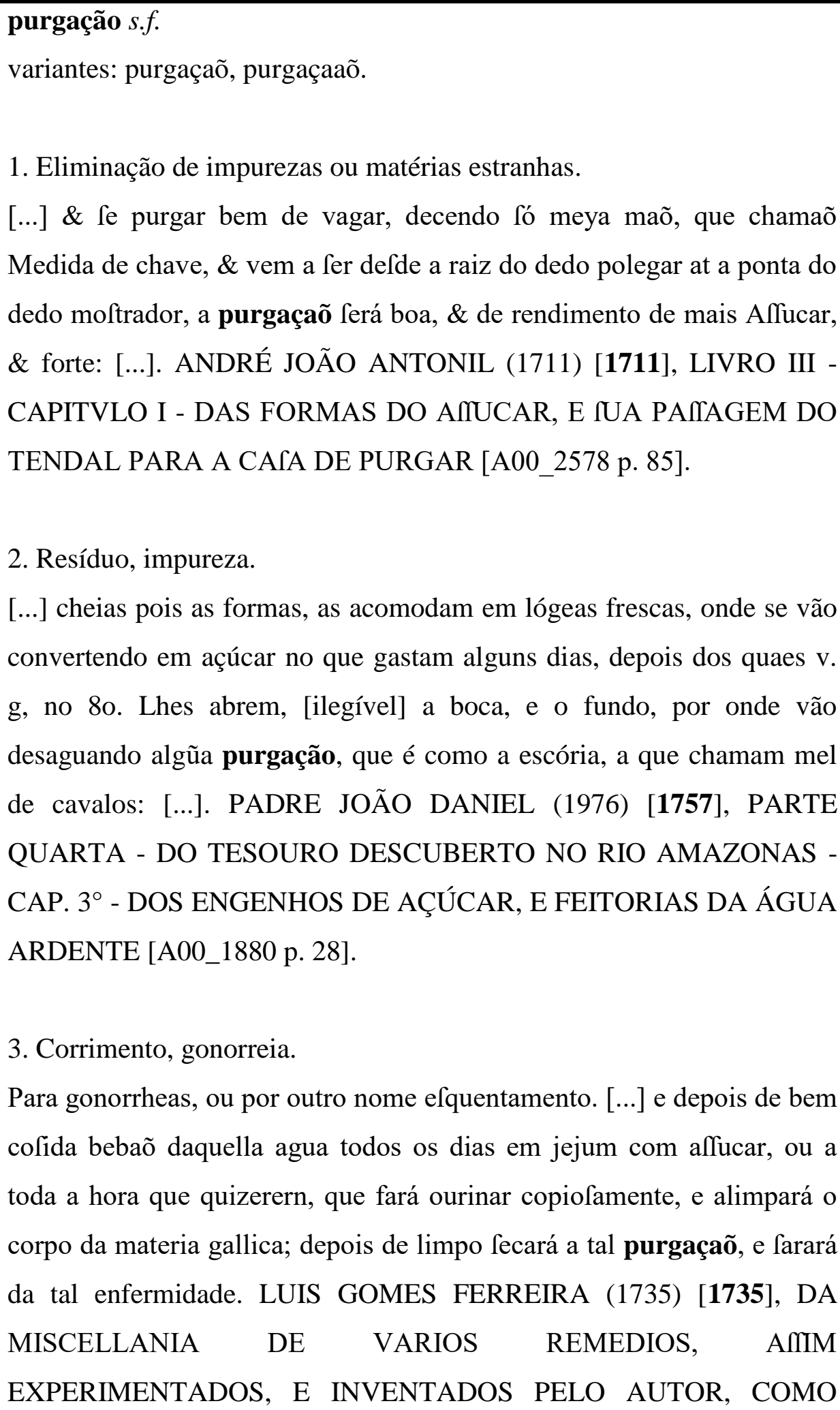 \\
\hline
\end{tabular}




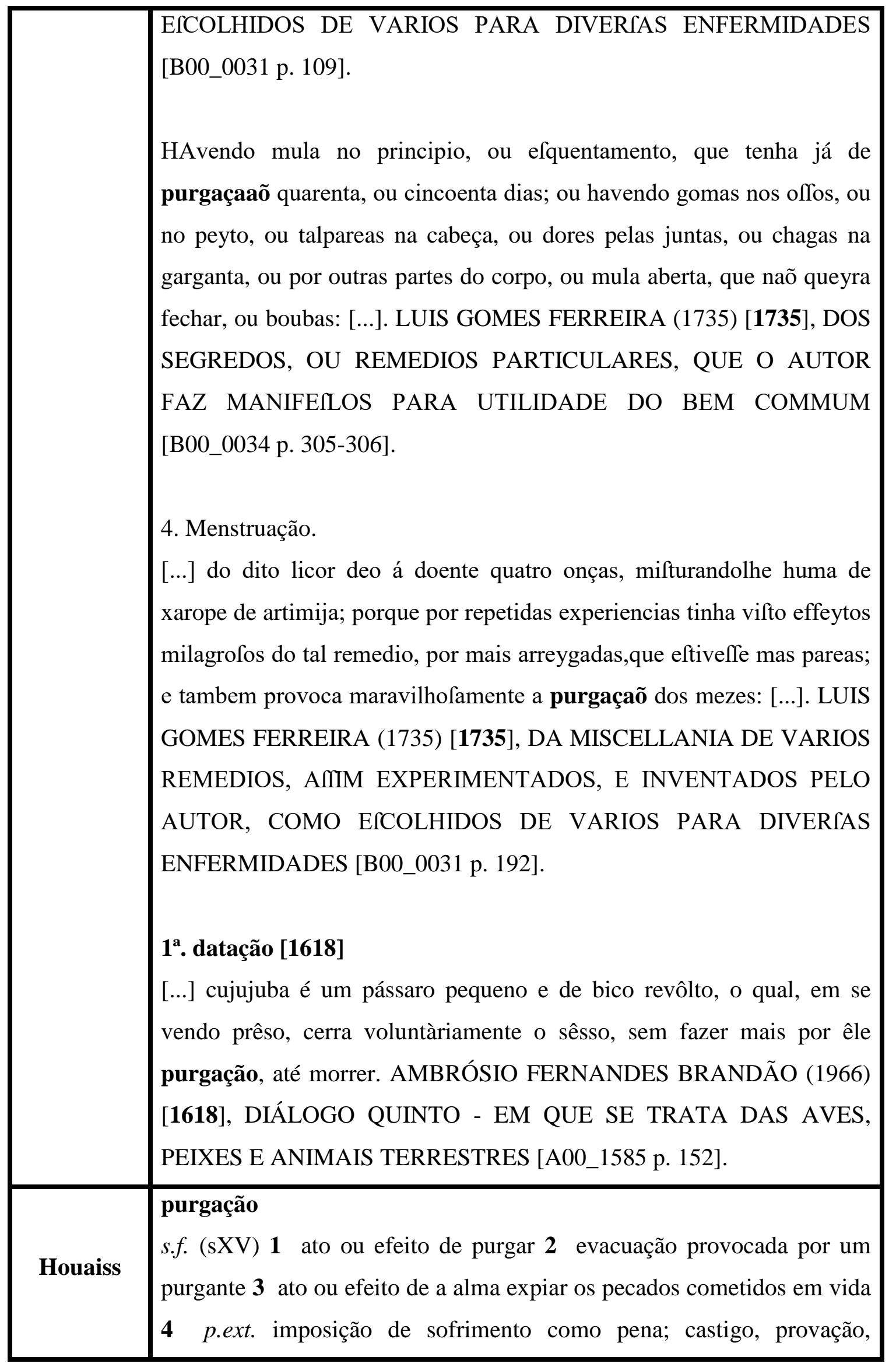


penitência 5 qualquer secreção patológica que escorra de um órgão; corrimento, supuração 6 m.q. gonorreia $\square$ ETIM lat. purgatìo,ónis 'limpeza; justificação' $\square$ SIN/VAR ver sinonímia de gonorreia

Fonte: elaboração própria.

A unidade lexical purgação, no DHPB, é associada à doença somente na terceira acepção, em que gonorreia se apresenta como sinônimo de corrimento - mais próximo, portanto, do sentido de blenorragia.

A primeira vez que a palavra aparece no Banco de dados do DHPB é em 1618, no entanto, não com o mesmo sentido. Contudo, podemos notar que os exemplos da acepção correspondente foram todos extraídos do Erário Mineral (FERREIRA, 1735), o que comprova que tal denominação para a doença surgiu no século XVIII.

Esquentamento, gonorreia e purgação sugerem, portanto, diferentes unidades lexicais que designam a mesma doença.

Esquentamento, por exemplo, é definido não somente em ambos os dicionários consultados como <<gonorreia $>$, como também pelos autores dos textos que perfazem nosso corpus de estudo. A unidade não possui marcas linguísticas, que comprovem que ela pertença a um domínio específico, mas é considerada tabu por Houaiss.

Gonorreia, por sua vez, é sinalizada como unidade lexical especializada pertencente à área da Dermatologia, em Houaiss, onde seu significado é remetido a blenorragia. Em relação a purgação, o DHPB resume o sentido denotado pela definição do Houaiss: <<corrimento, gonorreia >>.

A Sociedade Brasileira de Infectologia (SBI) traz em seu glossário de doenças não só a entrada gonorreia, como também as variantes blenorragia, esquentamento e purgação, identificadas como variantes populares da doença.

\section{Considerações finais}

Independente do contexto histórico, a gonorreia manifesta-se na população mundial há séculos, conforme pudemos comprovar, nunca tendo sido erradicada. Pelo contrário, está entre as principais doenças sexualmente transmissíveis que mais ocorrem 
no mundo nos dias de hoje, podendo "determinar desde infecção assintomática até doença manifesta, com alta morbidade" (SBI). A doença não é, portanto, decorrente das condições de trabalho nas minas do Brasil Colonial, mas sua propagação certamente está relacionada ao modo de vida da população.

Segundo o site da Revista Veja, desde que se estabeleceu em saúde pública a falência da erradicação do gonococo, é desejável que o tratamento atinja eficácia superior a 95\%. No entanto, a vigilância mundial à Neisseria gonorrhea demonstrou aumento da sua resistência a múltiplas classes de antimicrobianos.

De acordo com os resultados de nosso estudo metalexicográfico, concluímos que, embora gonorreia possua diferentes denominações/ variantes, podemos notar que não houve mudança linguística, uma vez que o termo mais antigo é o mais utilizado na atualidade.

\section{REFERÊNCIAS}

BIDERMAN, M. T. C.; MURAKAWA, C. de A. A. (coord.). Banco de dados do Dicionário Histórico do Português do Brasil - séculos XVI, XVII e XVIII. Araraquara: Laboratório de Lexicografia/FCLAr, acesso restrito. Disponível em: http://lablex.fclar.unesp.br/philologic. Acesso em: 18 jan. 2020.

BIDERMAN, M. T. C.; MURAKAWA, C. de A. A. (org.). Dicionário Histórico do Português do Brasil - séculos XVI, XVII e XVIII. Araraquara: Laboratório de Lexicografia/FCLAr. Não publicado.

BIDERMAN, M. T. C. Teoria Linguística: Teoria Lexical e Linguística Computacional. São Paulo: Martins Fontes, 2001.

CAMBRAIA, C. N. Da lexicologia social a uma lexicologia sócio-histórica: caminhos possíveis. Revista de Estudos da Linguagem, v. 21, n. 1, Belo Horizonte: UFMG, p. 157-188. 2013. 
DOMLADOVAC-SILVA, C. O léxico das enfermidades na obra Erário Mineral (1735), de Luís Gomes Ferreira. Orientadora: Clotilde de Almeida Azevedo Murakawa. 2017. 206 f. Dissertação (Mestrado em Linguística e Língua Portuguesa) - Faculdade de Ciências e Letras, Universidade Estadual Paulista "Júlio de Mesquita Filho", Araraquara, 2017.

FERREIRA, L. G. Erário Mineral. Lisboa Occidental: Officina de Miguel Rodrigues, 1735.

GOMES, B. A. Memoria sobre a Ipecacuanha Fusca do Brasil, ou cipó das nossas boticas. Lisboa: Arco do Cego, 1801.

GONORREIA. In: Sociedade Brasileira de Infectologia (SBI): Doenças: infecções sexualmente transmissíveis. Disponível em: https://www.infectologia.org.br/pg/986/gonorreia. Acesso em: 18 jan. 2020.

HOUAISS, A.; VILLAR, M. de S.. Dicionário Houaiss da Língua Portuguesa. Elaborado pelo Instituto Antônio Houaiss de Lexicografia e Banco de Dados da Língua Portuguesa. Rio de Janeiro: Objetiva, 2009. CD-ROM.

MATORÉ, G. La méthode en Lexicologie: domaine français. Paris: Marcel Didier, 1953.

MENDES, J. A. Governo de mineiros, mui necessário para os que vivem distantes de professores seis, oito, dez e mais léguas, padecendo por essa cauza is seus domésticos e escravos queixas, que pela dilaçam dos remédios se fazem incuráveis, no mais das vezes mortais. Oferecido ao Senhor Coronel Antonio Soares Brandão, cirurgião da Câmara de Sua Majestade Fidelíssima e Fidalgo de sua Casa, Cirurgião-mor dos Reinos, seus domínios e exércitos. Lisboa: Oficina de Antonio Roiz Galhardo, 1770. 
MIRANDA, J. C. de. Prodigiosa Lagoa descuberta nas Congonhas das Minas do Sabará, que tem curado a varias pessoas dos achaques, que nesta Relação se expõem. Lisboa: Officina de Miguel Manescal da Costa, 1749.

UIP, D. Gonorreia: a maior causa de doença transmitida por sexo no mundo. Veja, São Paulo, nov. 2017. Seção Saúde. Disponível em: https://veja.abril.com.br/blog/letra-demedico/gonorreia-a-maior-causa-de-doenca-transmitida-por-sexo-no-mundo/. Acesso em: 18 jan. 2020. 